\title{
As redes de autoatendimento bancário e os idosos: quais as características das ATMS que determinam sua rejeição
}

\author{
Sirlei Pitteri", Duilio Nachbar Júnior*, Alessandro Gustavo Santos Arruda***
}

\section{Resumo}

Este trabalho aborda a evolução das redes de autoatendimento bancário no sistema financeiro brasileiro e os desafios na utilização dos caixas eletrônicos pelos idosos. $\mathrm{O}$ objetivo do presente estudo foi investigar as características do autoatendimento, que se relacionam com as diversas dificuldades encontradas para a operacionalização das máquinas de caixas eletrônicos pelos idosos. A metodologia utilizada para este estudo constitui-se de pesquisas bibliográficas sobre equipamentos de autoatendimento, sobre o idoso e seu estilo de vida. A pesquisa de campo foi efetuada em caixas eletrônicos existentes no interior de uma agência bancária na região central de São Paulo, em dias e horários de grande concentração de idosos e pensionistas do Instituto Nacional de Seguro Social. Consistiu num questionário aplicado em duas fases: a primeira, com cinco questões, que teve como finalidade definir o instrumento de pesquisa final, composto por 15 questões. A pesquisa realizada neste estudo resultou em melhor compreensão de algumas questões, levantadas inicialmente, e em indicações que podem auxiliar futuros estudos, com o objetivo de melhorar a operacionalização dos caixas eletrônicos. De modo geral, ficou evidente que os idosos já foram conquistados pelo autoatendimento.

Palavras-chave: Ciência da informação. Assistência a idosos. Comportamento adaptativo.

\section{Introdução}

A reorganização do setor bancário, ainda que atrelada ao movimento em nível mundial, apresentou suas particularidades no Brasil. Larangeira (1997) elenca três peculiaridades principais: o caráter inflacionário de nossa economia,

* Mestre e doutoranda em Administração na Universidade Municipal de São Caetano do Sul. Graduada em Física pela Universidade de São Paulo. Professora do Instituto Nacional de Pós-Graduação e Universidade Municipal de São Caetano do Sul. Endereço para correspondência: Rua Pensilvânia, 742, apto 42. CEP 04564-002. São Paulo - SP. E-mail: sirlei_pitteri@uol.com.br.

** Graduado em Matemática pela Pontifícia Universidade Católica de São Paulo. Especialista em Gerenciamento Empresarial pela Pontifícia Universidade Católica de São Paulo.

**** Doutorando em Administração na Universidade Municipal de São Caetano do Sul. Mestre em Administração pela Universidade Federal de Minas Gerais. Professor da Universidade Federal de Minas Gerais e da Universidade Municipal de São Caetano do Sul.

$\hookrightarrow$ Recebido em agosto de 2009 - Avaliado em março de 2010.

$\hookrightarrow$ doi:10.5335/rbceh.2010.011 
a desregulamentação do mercado e a introdução do Plano Real. O processo inflacionário de nossa economia, característico deste a década de 1970 até o Plano Real, garantia boa rentabilidade ao sistema financeiro nacional, via aplicação dos passivos não remunerados (tais como depósitos à vista e recursos em circulação). Esse aporte de recursos possibilitou altíssimos investimentos em tecnologia de informática e telecomunicações por parte dos bancos.

Da mesma forma, a mudança provocada pela Constituição de 1988 possibilitou às instituições financeiras integrar diversos serviços, dando origem aos chamados "bancos múltiplos". Ampliaram-se, assim, a gama de produtos e serviços, o número de bancos e, consequentemente, a concepção do que é serviço bancário, antes orientado para a intermediação financeira simplesmente e, atualmente, voltado para a captação de diversos tipos de negócios. Toda sorte de atividades, desde a compra de seguros até a aplicação no mercado de capitais, é atualmente oferecida nas agências, modernamente renomeadas como "unidades de atendimento". Por fim, o Plano Real impôs novo nível de competição ao sistema. A diminuição da rentabilidade que antes se obtinha com a inflação estabeleceu um novo marco de competição: a produtividade e os ganhos de escala.

Em decorrência, verifica-se acentuada redução do número de bancos, resultado de falências, fusões, incorporações e aquisições, bem como de privatizações. O sistema bancário brasileiro, constituído em 1993 por 245 bancos, passou para 194 em 1999. (LARANGEIRA, 1997, p. 129).
Desse modo, os limites físicos das instituições financeiras foram expandidos para além dos convencionais e surgiram, ao longo da década de 1980, as redes eletrônicas de autoatendimento (ATM - Automatic Tellers Machine), que tiveram sua expansão ampliada na década de 1990, com a popularização da internet.

Investimentos significativos em tecnologia da informação têm sido uma das maiores prioridades das instituições financeiras ao longo dos últimos quarenta anos. O movimento intenso de fusões bancárias e a aquisição de bancos brasileiros por instituições financeiras transnacionais exigiram padronização nos sistemas de autoatendimento, de modo a simplificar os processos, tanto para os clientes como para as instituições financeiras.

O crescimento considerável do número de caixas eletrônicos e o acesso às contas bancárias pela internet aumentam a conveniência dos usuários de serviços bancários e permitem às instituições financeiras diminuir os riscos e custos operacionais. Desse modo, é possível operações automatizadas direto na conta bancária do cliente, sem a necessidade de emissão de cheques, digitações, conferências e autorizações necessárias no processamento tradicional.

Estudo realizado por Meirelles e Maia (2004) constatou que só entre 1998 e 2002 a quantidade de ATMs cresceu $26 \%$ a cada ano. No mesmo estudo constatou-se que "os bancos que alavancaram mais os seus ativos foram aqueles que mais investiram em informática", sobretudo quando analisado o período entre 2000 e 2003. 
Contudo, uma questão crítica para as instituições financeiras são as filas nos caixas nas agências bancárias. A questão levantada por diversos especialistas do setor é a seguinte: Por mais que se efetuem investimentos e esforços para direcionar os clientes ao autoatendimento, por que as filas dos caixas das agências aumentam a cada dia?

As instituições financeiras vêm concentrando esforços em ampliar sua rede de atendimento por meio do autoatendimento, em virtude das inúmeras vantagens que apresenta em relação ao atendimento tradicional. $\mathrm{O}$ crescimento do número de agências ou postos de atendimento permanece praticamente estável nos últimos sete anos. Os caixas eletrônicos são os responsáveis pela expansão da rede de atendimento das instituições financeiras, pois são instalados em locais de grande circulação de público. Hoje, essas formas de atendimento representam quase $80 \%$ das operações bancárias efetuadas por pessoas físicas. (RELATÓRIO..., 2007).

A despeito de um sem-número de restrições que obrigam as pessoas de qualquer faixa etária a enfrentar as intermináveis filas bancárias, uma hipótese que se apresentou e mereceu investigação, objeto deste estudo, seria a opção pelo atendimento pessoal por parte dos idosos, que apresentariam resistência à utilização de recursos tecnológicos. Essa hipótese se justifica pelo fato de que os adultos deste início de século, que estavam entrando na terceira idade quando se deu a explosão das redes de autoatendimento bancário, não tiveram contato com a tecnologia da informação ao longo de sua infância, adolescência e parte de sua vida economicamente ativa. É compreensível, portanto, que ocorram insegurança e desconforto ao operar máquinas de autoatendimento.

Com base nessa suposição, surgiram indagações sobre quais elementos estariam interferindo na escolha das pessoas da terceira idade pela utilização de caixas com atendimento pessoal em detrimento do autoatendimento eletrônico. A percepção de valor do cliente estaria sendo influenciada por aspectos sociais/psicológicos? Ou teria relação com a natureza técnica dos equipamentos de autoatendimento? Como as instituições financeiras poderiam facilitar a utilização dos caixas eletrônicos de modo a diminuir as filas dos caixas das agências? Que mecanismos poderiam ser adaptados ou criados para a desmistificação do autoatendimento para as pessoas da terceira idade?

Vários artigos têm sido escritos nesse sentido. Anjo Neto, Souza Neto e Gonçalves (2002), em estudo realizado em agências do Nordeste, já alertavam que existiam, por parte dos idosos, desconfiança e insegurança para realizar transações utilizando os ATMs. Em outro estudo, agora em Santa Catarina, Mazzoni e Torres (2008) constataram que "uma parcela expressiva da amostra analisada não possuía independência para trabalhar com os CAA, necessitando solicitar a ajuda de terceiros, seja para compreender o sistema ou para operar o mesmo". Do mesmo modo, Abensur et al. (2003), utilizando um modelo de simulação baseado na teoria das filas e aplicando este modelo em 
caixas do estado de São Paulo, "mostrou que os ganhos de produtividade com a introdução de máquinas especializadas são significativos".

Em vista de toda essa discussão, uma questão foi selecionada como foco de nossos estudos: Quais são as principais características das ATMs que os idosos rejeitam? Esse questionamento surge em razão da afirmação de Clarke (2001, p. 28), de que

o sucesso dessas máquinas está na confiança que os clientes depositam nelas e na avaliação realizada pelo cliente, quanto à sua própria capacidade de entendê-las e utilizálas. Se a máquina parecer muito difícil de ser utilizada, parecer passível de atuar de maneira inesperada, facilitar fraudes contra o cliente, gerar erros na conta dele ou colocar em risco sua segurança pessoal, ele não confiará na máquina e não utilizará.

É provável que alguns fatores possam influenciar negativamente na utilização dos caixas eletrônicos, dificultando ou até mesmo restringindo o autoatendimento pelos idosos. Algumas hipóteses foram levantadas e servirão de base para o presente estudo. As premissas iniciais foram as seguintes:

a) existem dúvidas quanto às informações disponíveis nos caixas eletrônicos, dificultando ou impedindo o autoatendimento;

b) existe insegurança ao utilizar os caixas de autoatendimento sem o auxílio ou intervenção de um atendente do banco;

c) existe receio com relação a fraudes e golpes nos caixas eletrônicos;

d) existem limitações físicas como dificuldades na leitura dos dizeres na tela dos caixas; e) as cédulas disponíveis nos caixas de autoatendimento não atendem às necessidades no caso de saques, como, por exemplo, do valor da aposentadoria;

f) os idosos preferem o atendimento pessoal, mesmo que para isso seja necessário aguardar na fila dos caixas.

Tentar compreender o comportamento do idoso para responder às questões que motivaram a realização desse estudo exigiu que fossem elaboradas algumas pesquisas bibliográficas, documentais e pesquisa de campo. Estão descritas a seguir as principais abordagens metodológicas utilizadas nas pesquisas.

\section{Materiais e métodos}

Este estudo restringiu-se aos caixas eletrônicos existentes no interior de uma agência bancária na região central de São Paulo, em dias e horários de grande concentração de idosos e pensionistas do Instituto Nacional de Seguro Social (INSS).

Para se obterem as informações necessárias, a fim de verificar as hipóteses previamente levantadas, foi realizada uma pesquisa em um grupo de cem pessoas, selecionadas de acordo com os critérios de faixa etária, uma vez que o objetivo do estudo é compreender como os idosos utilizam os caixas-eletrônicos. Foram entrevistadas pessoas com sessenta anos ou mais. No que se refere aos aspectos éticos, as avaliações não continham nenhum dado que identificasse o indivíduo e lhe causasse constrangimento ao responder; porém, do ponto de vista 
acadêmico, o projeto não foi submetido ao Comitê de Ética em Pesquisa da universidade. Foram incluídos no estudo os adultos que aceitaram participar voluntariamente, após obtenção de consentimento verbal.

$\mathrm{O}$ instrumento de pesquisa foi um questionário estruturado composto por quinze perguntas. O questionário adquiriu seu formato final após a elaboração de um pré-teste, composto por cinco perguntas iniciais. O objetivo do pré-teste foi avaliar o grau de entendimento das questões pelo público a ser pesquisado, conhecer os assuntos mais relevantes e obter indícios sobre quais perguntas poderiam ser formuladas, com base nos comentários feitos pelos entrevistados no pré-teste.

Segundo dados da Prefeitura Municipal de São Paulo (SÃO PAULO, 2008), a população total do Centro de São Paulo, administrada pela Subprefeitura da Sé, é de cerca de 415.000 pessoas, abrangendo uma área geográfica total de $37,3 \mathrm{~km}^{2}$, compreendendo dez distritos. $\mathrm{O}$ distrito República, selecionado para a pesquisa, apresenta-se em segundo lugar em população, com em torno de 48 mil pessoas. Foi definida uma amostra não probabilística por cotas de cem pessoas a serem entrevistadas, ou seja, cem respostas válidas, com índice de confiabilidade de $68,5 \%$, considerado ideal para fins acadêmicos, e com desvio-padrão de 0,05\% (CERVO; BERVIAN, 1983).

A pesquisa abordou aspectos qualitativos e quantitativos mediante entrevistas pessoais com os clientes idosos nas filas dos caixas tradicionais e dos caixas eletrônicos. Foi possível registrar atitudes, questionar os clientes em relação aos motivos os que levaram a optar pelos diferentes tipos de atendimento. Os períodos escolhidos para a elaboração da pesquisa foram cuidadosamente pensados em função da sazonalidade. Entre o primeiro e o quinto dia útel a demanda por saques bancários é muito alta, em razão dos pagamentos realizados pelas empresas e pelo INSS, responsável pelos créditos dos aposentados no período de 1 a 10 de cada mês. A escolha da agência bancária para a realização da pesquisa baseou-se nos critérios de porte da agência: médio a grande; perfil do público: média e baixa renda, localização geográfica: centro da cidade de São Paulo, acessível a um grande número de pedestres.

\section{Referencial teórico}

O terminal de autoatendimento bancário ${ }^{1}$ é um dispositivo eletrônico que proporciona aos clientes de uma determinada instituição financeira uma gama variada de serviços, como saque e depósito de numerário financeiro, verificação do saldo ou do extrato de suas contas bancárias e demais negócios e até a impressão de cheques sem a necessidade de um funcionário da instituição. $\mathrm{O}$ que caracteriza um autoatendimento é a possibilidade de o cliente interagir diretamente com os sistemas bancários e realizar suas transações sem depender de outra pessoa.

Os terminais de autoatendimento bancários foram originalmente lançados com o propósito de automatizar duas funções básicas: a de depositar e a de sacar dinheiro, direcionados apenas aos 
clientes com baixos saldos bancários. Porém, os clientes descobriram nos terminais de autoatendimento uma grande conveniência, pois são acessíveis 24 horas por dia. Além disso, de acordo com o Departamento Intersindical de Estatística e Estudos Sociais (DIEESE, 1997), a adoção de terminais de autoatendimento pode ser considerada uma estratégia de redução de custos, pois uma operação eletrônica custa, aproximadamente, dez vezes menos que o procedimento no caixa. (MEIRELLES; MAIA, 2004).

O Brasil tornou-se um dos líderes mundiais em números de caixas eletrônicos. De acordo com um levantamento concluído em junho de 2005 pelo Banco Central do Brasil (BACEN, 2008), o país possuía 140 mil máquinas que permitiam saques e depósitos, perdendo apenas para os Estados Unidos, que possuíam 370 mil.

As instituições financeiras brasileiras começaram a investir em redes de autoatendimento no início da década de 1980. Os bancos pioneiros planejavam suas estratégias de marketing em torno da vantagem competitiva que os caixas eletrônicos ofereciam, como uma ferramenta de conquista e fidelização de clientes. Segundo Abensur et al. (2004), estrategicamente, as tecnologias de informação adotadas pelos bancos podem funcionar como barreiras de entrada, substitutos aos serviços bancários tradicionais e instrumentos de operacionalização de uma estratégia genérica de liderança em custo.

A grande expansão, no entanto, ocorreu da década de 1990, quando os bancos perceberam que os caixas ele- trônicos eram um instrumento poderoso para reduzir seus custos operacionais. $\mathrm{O}$ processo bancário das operações tradicionais envolve, a rigor, três funcionários da instituição: o primeiro digita a operação no computador, o segundo confere e o terceiro autoriza. Com o autoatendimento, o cliente digita e autoriza sua transação, ficando sob a responsabilidade da instituição apenas a conferência, o que reduz o volume de processamento para um terço do sistema tradicional.

De acordo com a Federação Brasileira de Bancos (FEBRABAN, 2008), em pesquisa realizada entre 2002 e 2006 constatou-se que os terminais de autoatendimento apontam um crescimento da ordem de $10 \%$ ao ano, ao passo que o número de usuários cresceu $36 \%$ no mesmo período. Esses dados demonstram a crescente aceitação do autoatendimento pelos usuários.

Esses equipamentos para autoatendimento bancário são projetados, construídos e instalados de acordo com critérios e parâmetros técnicos da Associação Brasileira de Normas Técnicas - NBR 15250/2005² (ABNT, 2008). Para o estabelecimento desses critérios e parâmetros técnicos, foram consideradas diversas condições de mobilidade e de percepção, com ou sem a ajuda de aparelhos específicos, sejam eles sistemas de voz, cadeira de rodas ou outro que complemente necessidades individuais.

Diretamente, a NBR 15250/2005 não faz menção aos idosos, porém observa-se que existe a preocupação com o desenho universal ${ }^{3}$. O conceito de desenho universal tem como pressupostos a equiparação nas possibilidades de uso, flexibilidade 
no uso, uso simples e intuitivo, captação da informação, tolerância para o erro, dimensão e espaço para o uso e interação. Todas essas premissas devem ocorrer de forma autônoma e segura.

Existe toda uma ciência preocupada com a interação do ser humano com a máquina: a ergonomia cognitiva. Trata-se de um campo de estudos da aplicação da ergonomia, cujo objetivo é buscar compreender como se articulam os processos cognitivos das pessoas diante de situações que envolvam resolução de problemas em diferentes níveis de complexidade. É importante salientar, contudo, que essa não tem como objetivo elaborar teorias gerais sobre a cognição humana. O seu papel é compatibilizar as soluções tecnológicas com as características e necessidades dos usuários. Nesse ângulo, é utilizada para contribuir com um referencial teórico e metodológico que permita analisar como o trabalho afeta a cognição humana. Para Abrahão, Silvino e Sarmet (2005, p. 163, apud SALERMO JUNIOR, 2008),

A relação entre trabalho e cognição humana traz o pressuposto de que cada novo equipamento e/ou interface, altera a natureza da tarefa a ser realizada e exige dos usuários competências diferenciadas para ação. Da mesma forma, novas interfaces são criadas no intuito de solucionar problemas de desempenho humano. É nessa perspectiva que a ergonomia cognitiva busca compreender a cognição humana em um contexto de ação e voltada para um objetivo específico.

Um trabalho interessante nesta área é o de Kuchinomachi e Kumada (1999), que buscaram classificar, entre os dez aparelhos eletrônicos de uso cotidiano dos idosos no Japão, os mais difíceis de serem operados, dadas suas restrições cognitivas e comportamentais. Para classificá-los os autores utilizam cinco tipos de cognição: memória, raciocínio, atenção, julgamento e controle emocional. Dentre os três aparelhos mais difíceis, constataram que o ATM é um, principalmente quanto ao quesito controle emocional.

No que se refere à interação dos idosos com os equipamentos de autoatendimento, as ATMs, uma das primeiras preocupações é com o tipo e tamanho de letra a ser utilizada na tela do equipamento; acuidade visual em vários níveis após a melhor correção ótica possível. Isso se deve ao fato de ser uma característica natural do envelhecimento a diminuição da visão. Considera-se que para a utilização de um caixa de autoatendimento bancário a pessoa com baixa visão deve fazer uso dos mesmos recursos destinados às pessoas com deficiência total de visão.

Outra preocupação que favorece os idosos são as letras e símbolos impressos nas máquinas, com traços simples, verticais e regulares, evitando-se padrões ou traços internos, fontes itálicas, recortadas, manuscritas, com sombras, sublinhadas, com aparência tridimensional ou distorcidas, excessivamente largas, altas ou finas. A norma recomenda ainda que se utilizem cores que possam ser diferenciadas por pessoas portadoras de cromodeficiências ${ }^{4}$.

Cada vez mais a sociedade toma consciência de que a população está envelhecendo. No Brasil, configura-se um tema atual e amplamente discutido, em virtude dos avanços da medicina, da 
diminuição das taxas de fecundidade e natalidade e do desenvolvimento de tecnologias, que apontam um aumento na expectativa e qualidade de vida, consequentemente ampliando a longevidade.

Autores divergem na identificação de um conceito para a velhice. Dentre muitos atributos classificatórios para a velhice, além da idade física, devem ser considerados aspectos sociais e culturais nos quais o indivíduo está inserido, aspectos biológicos, estilo de vida e outros. Formalmente, as leis brasileiras atribuem à velhice uma categoria de idade.

Em tempos remotos, filósofos e estudiosos teceram comentários sobre a velhice e alguns estimaram que o apogeu do corpo humano ocorresse em meados de sua existência. Platão (427-347 a.C.) afirmava que a velhice fazia surgir nos seres humanos um imenso sentimento de paz e de libertação. Para Hipócrates (460-370 a.C.), médico famoso da antiguidade grega, a velhice começaria depois dos cinquenta anos. Já Aristóteles (384-322 a.C.), discípulo de Platão, concluiu que o corpo humano chegaria à sua perfeição aos 35 anos e sua alma, aos 56 anos. (GARCEZ LEME, 2007). Dante Alighieri acreditava que se atinge a velhice aos 45 anos. (VARGAS, 1994).

$\mathrm{Na}$ sociedade ocidental, costumase dizer que a idade determinante da velhice é 65 anos, quando se encerra a fase economicamente ativa da pessoa e começa a aposentadoria. Com base no Censo 2000 do Instituto Brasileiro de Geografia e Estatística (IBGE, 2006), os idosos representam 14,5 milhões de pessoas, ou seja, $8,6 \%$ da população total do Brasil. O Censo 2000 classifica como idosas pessoas com anos ou mais. A expectativa é que em 2020 a população com mais de sessenta anos no país deva chegar a 30,9 milhões de pessoas, aproximadamente $13 \%$ do total. Os brasileiros vivem atualmente mais do que o dobro do tempo que se vivia há um século. Em 1900, a expectativa de vida média dos brasileiros era de 33,7 anos. De acordo com a mais recente Tábua de Vida do IBGE (2006), a população brasileira alcançava a esperança de vida ao nascer de 72,05 anos, sendo 68,4 anos entre os homens e 75,9 anos entre as mulheres. A previsão para a expectativa de vida em 2030 será de 74,9 anos para os homens e 81,9 para as mulheres.

O envelhecimento é um processo ininterrupto ao longo da vida, natural de todos os seres vivos, que provoca no organismo modificações biológicas, psicológicas e sociais. As modificações biológicas e as morfológicas são graduais e progressivas, reveladas por aparecimento de rugas e perda da elasticidade e viço da pele; diminuição da força muscular, da agilidade e da mobilidade das articulações; aparição de cabelos brancos e perda dos cabelos entre os indivíduos do sexo masculino; redução da acuidade sensorial, da capacidade auditiva e visual; distúrbios do sistema respiratório, circulatório; alteração da memória e outras.

De acordo com Vargas (1994), nos idosos a taxa metabólica é mais baixa, o que torna mais lenta o troca de energia; por isso, seus recursos de autoexpressão comportamental vão se tornando gradualmente também reduzidos. As modificações fisiológicas nos idosos estão 
relacionadas às alterações das funções orgânicas. As modificações psicológicas ou psicossociais ocorrem quando o ser humano que envelhece necessita se adaptar a cada situação nova do seu cotidiano.

Por outro lado, as modificações sociais são verificadas quando as relações sociais se tornam alteradas em razão da diminuição da produtividade e, principalmente, do poder físico e econômico, sendo a alteração social mais evidente em países de economia capitalista. Trata-se de modificações afetivas e cognitivas: efeitos fisiológicos do envelhecimento, consciência da aproximação do fim da vida, suspensão da atividade profissional por aposentadoria; sensação de inutilidade, solidão, afastamento de pessoas de outras faixas etárias, segregação familiar, dificuldade econômica, declínio no prestígio social, de experiências e valores e outras. (VARGAS, 1994; GARCEZ LEME, 2007; SIMÕES, 1994).

Em muitas culturas e civilizações, principalmente as orientais, o cidadão velho - o idoso - é visto com respeito e veneração, representando uma fonte de experiência, do valioso saber acumulado ao longo dos anos, da prudência e da reflexão. Entretanto, em outras culturas é atribuído ao idoso caráter pejorativo, por representar o velho, o ultrapassado e a falência múltipla do potencial do ser humano. Essa expressão da realidade vivida em muitas culturas é confirmada pela afirmação feita por Simões (1994), de que o velho significa "perda, deterioração, fracasso, inutilidade, fragilidade, antigo, que tem muito tempo de existência, dando a impressão de que o velho vive improdutivamente e está ultrapassado pela nossa sociedade".

$\mathrm{Na}$ tentativa de suavizar essa conotação pesada e negativa atribuída ao termo "velho", inúmeros eufemismos têm sido usados pela mídia e pela sociedade de modo geral para classificar as pessoas acima de sessenta anos, tais como "terceira idade", "melhor idade", "boa idade", entre outros. No entanto, o retrato que se configura atualmente em algumas regiões brasileiras indica padrões de comportamentos diferenciados para os idosos, os quais estão longe de serem considerados inativos.

Apesar da aposentadoria, muitos idosos continuam economicamente produtivos, atuando em trabalhos muitas vezes informais. Muitos idosos aproveitam esta fase da vida para se dedicar a hobbies, como caminhar e dançar, programar viagens com grupos de terceira idade; alguns se ocupam com trabalhos voluntários em comunidades carentes ou hospitais; outros desenvolvem trabalhos manuais, como tricô, crochê e tear manual, ou outros trabalhos artesanais. De modo geral, os idosos procuram manter a forma física praticando exercícios e $o$ equilíbrio físico e mental com a prática de tai chi chuan, ou dedicam-se a curtir os netos.

Os comportamentos ou hábitos descritos rompem com estereótipos dos que acreditam que a idade avançada, ou seja, a velhice, é sinônima de estagnação, desânimo, declínio e improdutividade. É inegável a limitação do organismo humano diante do avanço da idade. No entanto, da mesma maneira, são incontestáveis as formas que os seres 
humanos têm encontrado de burlar e, muitas vezes, barrar o processo de envelhecimento, com o apoio da medicina, tornando-se ativos e produtivos por muito mais tempo.

A ideia de uma etapa de declínio tem sido substituída pela consideração de que os estágios mais avançados da vida são momentos favoráveis para novas conquistas, guiadas pela busca da satisfação e realização pessoal. Essa é uma visão atual bem mais otimista do que a apresentada pela escritora, filósofa existencialista e feminista francesa Simone de Beauvoir (1990) em seu famoso ensaio sobre a velhice, no qual aborda o processo de envelhecimento e tece críticas apaixonadas sobre a atitude da sociedade para com os anciãos.

Compreender a visão de mundo dos idosos neste início do século XXI sugere uma pesquisa sobre fatos históricos que permearam as sociedades e influenciaram na vida dessas pessoas desde sua infância. O século XX foi palco de acontecimentos que moldaram as gerações, seus hábitos e atitudes, modo de agir e pensar, e atribuíram diferentes valores aos seus membros. Convicções, expectativas, esperanças foram criadas e derrubadas. Pesquisas bibliográficas e documentais apontam uma cronologia, seguida por diversos autores (WACHHOLZ; FIAMONCINI, 2006; CONGER, 1998; GILBURG, 2007), que delimita o início e o fim das gerações, em face das grandes transformações ocorridas no cenário econômico, social, político e cultural ao longo do século passado.

Algumas variações sobre o início e o final de cada geração são divergentes entre os autores pesquisados, porém não interferem de modo significativo na tentativa de interpretação do perfil sociocultural das pessoas que pertencem às gerações e que fundamentam as premissas utilizadas nas análises das pesquisas realizadas. Embora os perfis sejam identificados na sociedade norteamericana, é possível fazer um paralelo com a sociedade brasileira, uma vez que características socioculturais brasileiras sofreram influências relevantes do modo de vida norte-americano, especialmente no pós-guerra, a partir de 1945.

Para efeito deste estudo será considerada a seguinte classificação: Geração da Segunda Guerra Mundial (1914 a 1929), Geração Silenciosa (1930 a 1945), Geração Baby Boomer (1946 a 1964), Geração X (1965 a 1981) e Geração Y (1982 a 2005).

As três gerações foco deste estudo são Geração da Segunda Guerra Mundial (1914-1929), Geração Silenciosa (1930-1945) e Geração Baby Boomer (1946-1964). Desse modo, objetiva-se uma melhor compreensão sobre quem são as pessoas nascidas sob as influências de cada período, que possam refletir em suas atitudes atualmente, em especial no que diz respeito ao tema central deste trabalho: a utilização dos caixas eletrônicos.

As pessoas nascidas entre 1914 e 1929 eram jovens com idades entre 20 e 24 anos quando eclodiu a Segunda Guerra Mundial (1939). No panorama mundial, muitos sofreram e foram afligidos pela agonia que o evento trouxe. Foi uma época marcada por profundas consequências físicas, morais, psicológicas, 
culturais, econômicas, entre outras, com reflexos em todos os níveis sociais. Estes jovens também receberam o impacto da Grande Depressão $0^{5}$, cujos efeitos devastaram famílias, empresas e economias nacionais.

No Brasil, essa geração surgiu pouco depois do final do Império e início da Primeira República (1889), período marcado pelo surgimento e consolidação da classe média, do proletariado urbano e pelo crescimento do número de imigrantes, procedentes, principalmente, da Europa e do Japão. A entrada na fase adulta por esses jovens foi marcada por momentos conturbados no Brasil, com o crescente autoritarismo, intervenção do Estado na economia e centralização do poder pelo golpe de estado que colocou Getúlio Vargas no comando. A repressão e autoritarismo do Estado influenciaram os jovens daquela época, que viviam sob o suporte financeiro dos pais e tinham de acatar com severa resignação as determinações que lhes eram impostas. Os meios de comunicação de massa eram inexistentes e os valores eram transmitidos pela família, destacando o respeito e valor atribuídos aos indivíduos com mais idade e experiência de vida. Desse modo, os laços afetivos eram mais fortes e o sentido de coletividade, mais presente. Apesar do pessimismo dos pais em face das privações e dificuldades vividas, os jovens daquela época acreditavam num futuro melhor para si. (WACHHOLZ; FIAMONCINI, 2006; CONGER, 1998; GILBURG, 2007).

A Geração Silenciosa (1930-1945) é formada pelos veteranos da Segunda Guerra Mundial. São vítimas dos distúr- bios emocionais e sociais e das incertezas vividas pelos muitos conflitos localizados em diferentes países, num período em que, aparentemente, o mundo estava em paz. Nascidos antes da era da televisão, essas pessoas conviveram no período da Guerra Fria, processo que dividiu o mundo em dois grandes blocos, liderados pela União Soviética e Estados Unidos. Esta fase foi muito mais complexa do que uma questão de ideologia política. Arbex $\mathrm{Jr}$ (s.d, s.p.) expressa bem os sentimentos da época: "[a guerra fria] teve uma dimensão cultural, que colocou em movimento um jogo simbólico do bem contra o mal [...] ela mexeu com a imaginação das pessoas, criou e reforçou preconceitos, ódios e ansiedades [...]".

No plano político, os cidadãos vivenciaram no Brasil a instituição da Segunda República, que se estendeu de 1945 até o golpe militar de 1964. Em meio a tantos conflitos, nacionais e internacionais, à insegurança que predominava na sociedade, nos governos, nas instituições, os jovens absorveram essa carga emocional e, sem saber como lidar com ela, simplesmente silenciaram, buscando refúgio em seu mundo interior, fechando-se ao mundo externo, assumindo uma postura soturna, sem expectativas futuras. Daí advém o nome atribuído a esta geração: Geração Silenciosa. A Geração Silenciosa também ficou conhecida pelo termo "burocratas". (CONGER, 1998).

No campo profissional, o espelho que se tem da Geração Silenciosa reflete sua imagem até a atualidade. São pessoas altamente leais às empresas em que trabalham, que respeitam o sistema hierárquico sem ousar se sobrepor a 
ele. As decisões superiores são sempre acatadas e nunca questionadas. As pessoas pertencentes à Geração Silenciosa costumam trabalhar por muitos anos em uma única empresa, sempre mantendo um relacionamento formal e cheio de cerimônias com seus superiores. (CONGER, 1998).

A Geração Baby Boomer (1945-1964), também conhecida como Geração Vietnã ou Geração do Rompimento, é considerada o fruto da explosão demográfica após a Segunda Guerra Mundial. Daí a expressão boomer, em tradução aproximada "pertencente ao boom", que em inglês significa explosão. Os acontecimentos, a partir do momento em que os Estados Unidos e as Forças Aliadas declararam a vitória sobre os nazistas, provocaram mudanças sociais importantes. Os soldados retornaram aos seus lares; a economia norte-americana teve sua força renovada. Esse clima favorável, de esperança e crescimento econômico, propiciou o aumento da natalidade, explicando a explosão demográfica que houve nessa época, que atingiu seu ponto máximo em 1957, permanecendo estável até 1965, quando começou a diminuir. (CONGER, 1998).

Essa geração de crianças nascidas no pós-guerra foi cercada de cuidados e mimos, protegidas das dificuldades vividas por seus pais e familiares, vivenciando oportunidades aparentemente ilimitadas. (WACHHOLZ; FIAMONCINI, 2006). Foi durante a geração Baby Boomer que surgiu a televisão e, com ela, um mundo novo foi descortinado, cheio de novidades, exaltação à juventude, estímulo ao consumismo, trazendo às outras culturas o chamado american way of life. (NETTO, 2007).

Mais do que produtos e empresas norte-americanos que chegaram ao Brasil, vieram embutidos seus hábitos e costumes, auxiliados pelo poder da televisão. Desse modo, os valores da sociedade brasileira transformaram-se com a incorporação dos hábitos de consumo norte-americanos. A participação da televisão na vida dos Baby Boomers foi, portanto, fundamental e marcante, uma vez que cresceram em frente à $T V$, podendo compartilhar com outras pessoas da mesma idade, independentemente de onde elas estavam, fatos e eventos culturais, além de programas de entretenimento.

Surgiu nessa fase o mito de que os adultos não compreendiam os jovens. $\mathrm{O}$ sentimento de ceticismo da autoridade, a confiança em si mesmos e a valorização da independência levaram a que essa geração também ficasse conhecida como a "Geração do Eu". A independência feminina ganhou um reforço na década de 1960 com a chegada dos anticoncepcionais ao mercado, que propiciaram maior segurança e controle às mulheres, contribuindo para o surgimento do movimento feminista e para a liberdade sexual. (WACHHOLZ; FIAMONCINI, 2006).

Esta foi uma geração completamente atípica se comparada às demais, conhecida por sua rebeldia e indulgência. Em contrapartida, foi a época em que os cursos universitários se popularizaram, o que contribuiu para que essa geração tivesse consciência de suas potencialidades. (CONGER, 1998). A expressão de suas opiniões, contrárias às autoridades, 
fez surgir os movimentos de protestos estudantis, populares e operários. Os boomers também foram líderes no movimento dos direitos civis, movimento feminista, direitos dos homossexuais, dos deficientes e direito à privacidade; estiveram na vanguarda da expansão da liberdade; na década de 1980, lideraram o movimento Diretas Já6.

Paralelamente, o sentimento de autoafirmação levou os jovens a saírem em busca de empregos. No campo organizacional, tiveram de conviver com os envelhecidos remanescentes da Geração da Segunda Guerra Mundial e da Geração Silenciosa, extremamente conservadores e tradicionais, em sua maioria, gerando conflito entre as gerações. Os sistemas de hierarquia predominantes e altamente respeitados das gerações anteriores não fizeram, nem fazem, o perfil dos Baby Boomers.

Foi durante essa geração que o trabalho em equipe se popularizou, bem como os funcionários tornaram-se mais dinâmicos e menos leais às empresas, acrescentando um ar de informalidade aos relacionamentos no local de trabalho. Apesar da tendência à baixa lealdade às empresas, os Baby Boomers, como profissionais, são conhecidos por workaholics, em razão do seu empenho e dedicação total ao trabalho, renegando muitas vezes a vida pessoal a segundo plano. Esse empenho, de certa forma, sugere que o trabalho é o provedor de recursos para a manutenção de outra tendência desta geração, a de consumista.

Essa tendência ao consumismo não passa despercebida aos publicitários ou profissionais da área de marketing de empresas de vários setores, como o bancário, os quais possuem produtos e serviços específicos para atender as pessoas dessa geração que hoje estão entrando na terceira idade. Os jovens dessa geração deixaram seus lares para viverem sozinhos por volta dos vinte anos, "rompendo suas raízes". (WACHHOLZ; FIAMONCINI, 2006).

\section{Resultados}

Para a validação ou não das hipóteses levantadas no início do presente estudo, foram entrevistadas cem pessoas, sendo 58 na faixa etária entre 60 e 84 anos (Geração Silenciosa) e 42 entre 56 e 62 anos (Geração Baby Boomer). No período em que foi realizada a pesquisa, o fluxo de homens da terceira idade pela agência foi $22,2 \%$ maior do que o de mulheres e $86 \%$ das pessoas são alfabetizadas, em maior ou menor grau de instrução. Os principais resultados da tabulação da pesquisa estão detalhados na Tabela 1, que aponta a quantidade de concordâncias com as afirmativas propostas. 
Tabela 1 - Resultados da pesquisa.

\begin{tabular}{lc}
\hline \multicolumn{1}{c}{ Afirmativa } & Respostas \\
\hline Receio de fraudes e golpes no caixa eletrônico & 94 \\
Adequação do horário de atendimento para suas necessidades & 94 \\
Mantêm-se concentradas enquanto realizam as operações & 81 \\
Saldos e saques são as transações mais realizadas & 73 \\
Existem caixas eletrônicos próximos à residência ou local de trabalho & 70 \\
Conseguem identificar funcionários que possam auxiliar nas transações & 67 \\
Boa iluminação dos ambientes com caixas eletrônicos & 61 \\
Enxergam de forma clara as letras na tela dos caixas eletrônicos & 61 \\
Informações sobre o passo a passo são suficientes & 61 \\
Presenças de estranhos no ambiente causam preocupação & 61 \\
Sentem-se aliviadas ao terminar suas transações no caixa eletrônico & 60 \\
Preferem realizar suas transações bancárias em caixas convencionais ${ }^{7}$ & 57 \\
Senha não é conhecida por outras pessoas, nem mesmo familiar & 57 \\
Ficam nervosas ao utilizarem o caixa eletrônico & 53 \\
Tenho dúvidas ao utilizar o caixa eletrônico: as informações não são claras & 48 \\
Conversam com estranhos confortavelmente no ambiente & 44 \\
Pedem ajuda a terceiros para realizar suas operações & 43 \\
Sentem falta de moedas e notas pequenas para troco & 32 \\
Lembram-se da senha eletrônica com facilidade & 31 \\
Limpeza dos ambientes com caixas eletrônicos, boa ou satisfatória & 25 \\
Preferem receber auxílio de um parente para realizar a transação & 3 \\
\hline
\end{tabular}

A preferência das pessoas da terceira idade é, de fato, pela utilização dos caixas com atendimento por meio de pessoas, em detrimento aos caixas eletrônicos, de acordo com a percepção inicial deste trabalho. Também ficou claro que a maioria dos idosos consegue identificar quem são os funcionários do banco que estão disponíveis a prestar auxílio aos clientes, principalmente àqueles que estão utilizando os caixas eletrônicos. Isso se deve ao fato de esses funcionários se apresentarem uniformizados e portando crachá de identificação.

A preocupação com a presença de estranhos no ambiente dos caixas eletrônicos também foi citada pela maioria e que não se sentem à vontade para conversar com outras pessoas neste local. As pessoas que se sentem livres para conversar passaram uma percepção de que é até agradável, por ser um momento de contato com outras pessoas da mesma idade.

Como a maioria prefere realizar suas transações no caixa com atendimento por meio de pessoas, justamente para evitar erros e ter seus problemas resolvidos por um funcionário, também se revelou nas repostas dadas a preferência quanto ao auxílio no caixa eletrônico ou à realização da operação sozinhos. Para 57\% dos idosos a preferência é pela colaboração de um funcionário no autoatendimento no caixa eletrônico. 
Embora a ida ao banco pareça não alterar o estado psicológico, conforme declarado pelos respondentes, $53 \%$ dos entrevistados sentem-se nervosos no momento de utilizar o caixa eletrônico. A psicologia explicaria esse fato como o momento da incorporação da realidade, pois até aquele instante não teriam se dado conta de que chegou a hora de colocarem suas habilidades de concentração na realização das operações. Até aquele momento foi a necessidade que prevaleceu. Daquele ponto em diante, é a realidade da execução de uma operação que assume o controle da situação. Por esse mesmo motivo, $60 \%$ das pessoas da terceira idade sentem-se aliviadas ao deixar o caixa eletrônico assim que terminam uma operação bancária.

Em relação às dificuldades de utilização dos caixas eletrônicos encontradas, $61 \%$ afirmaram que as informações apresentadas são claras, de fácil compreensão. A maioria (59\%) também declarou enxergar os dizeres da tela. A clareza das informações e a facilidade de leitura não se configuraram, portanto, em um fator de empecilho para transação ou a utilização do caixa eletrônico.

Para a maioria (68\%), as cédulas disponíveis no caixa eletrônico atendem às necessidades. Acreditava-se que a falta de moedas ou notas de menor valor seria um fator relevante para a maioria das pessoas da terceira idade. As reapostas revelaram que apenas $32 \%$ das pessoas entrevistadas gostariam de encontrar cédulas de menor valor nos caixas de autoatendimento.

$\mathrm{O}$ receio com relação a fraudes e golpes é quase unânime entre as pessoas da terceira idade, ou seja, $94 \%$ dos entrevistados afirmaram não se sentirem seguros nessas operações. No entanto, seriam necessárias outras pesquisas para confirmar se essa é uma preocupação apenas dos idosos ou estende-se para qualquer faixa etária.

A utilização da senha no caixa eletrônico também não é motivo de dificuldades. Dentre as pessoas da terceira idade entrevistadas, $69 \%$ declararam se lembrarem da sua senha. Também declararam conseguir digitá-la facilmente, o que é fácil de ser entendido, pois afirmaram enxergar facilmente os dizeres da tela; portanto, também conseguem enxergar as letras constantes no teclado.

Ainda com relação à senha, $57 \%$ das pessoas da terceira idade afirmaram que nenhuma outra pessoa tem conhecimento dela, por motivo de segurança, nem mesmo os familiares. Também declararam que não as associam com situações da vida pessoal (56\%), ou datas de aniversários. Preferem utilizar números aleatórios de fácil assimilação.

\section{Conclusão}

De acordo com os resultados descritos, pode-se afirmar que a preferência das pessoas da terceira idade é, de fato, pela utilização dos caixas com atendimento por meio de pessoas, em detrimento dos caixas eletrônicos, de acordo com a percepção inicial deste trabalho. As demais hipóteses, relacionadas a possíveis questões técnicas dos equipamentos de autoatendimento, não se comprovaram. Desse modo, pode-se concluir que as filas dos caixas tradicionais das instituições 
financeiras representam para os idosos algo mais do que um processo para a realização uma transação bancária. $\mathrm{O}$ interior da agência de uma instituição financeira é um espaço social, onde os idosos encontram pessoas com quem conversar, trocar experiências e demonstrar que possuem uma vida ativa, executando tarefas úteis que exigem habilidades intelectuais.

Por outro lado, o receio de golpes ou fraudes, confirmadas por $94 \%$ dos respondentes, merece um estudo mais amplo, que envolva usuários de todas as faixas etárias. Desse modo, é possível que um melhor gerenciamento da segurança dos equipamentos e uma comunicação eficaz tragam mais conforto aos usuários dos caixas-eletrônicos e, para as instituições financeiras, que as filas dos caixas sejam gradativamente esvaziadas.

Apesar de esse receio se configurar como um problema marcante para quase todos os entrevistados, $43 \%$ dos entrevistados preferem utilizar o caixa eletrônico ao caixa tradicional.

A despeito de se verificarem algumas diferenças de comportamento entre as duas gerações estudadas _ Geração Silenciosa e a Geração Baby Boomer _, as dificuldades para o uso da tecnologia são comuns a ambas, porém a aceitação é bastante positiva. Conforme apontado pela literatura, há uma tendência de as demais gerações que estão envelhecendo, mais familiarizadas com a tecnologia da informação, sentirem receio e dificuldades em menor grau. Portanto, a utilização dos caixas eletrônicos apresenta-se como um hábito consolidado e aparen- temente definitivo para as próximas décadas.

Uma sugestão de estudo para futuros trabalhos pode ser a questão do receio de fraudes e golpes, que exigem maior segurança e comunicação eficaz para tranquilizar as pessoas nesse sentido.

Networks self-service banking and the elderly: what are the characteristics of ATMS that determine its rejection

\section{Abstract}

This paper discusses the evolution of selfservice banking in the Brazilian financial system related with challenges in the use of ATMs by the elderly. The aim of this study was to investigate the characteristics of self-service banking that relate to the various difficulties encountered in the operation of ATM machines for the elderly. The methodology used for this study consisted of literature searches on ATMs machine and on the elderly and their lifestyle. Field research was conducted on existing ATMs inside a bank branch in central Sao Paulo, days and times of high concentration of elderly, retired from the National Institute of Social Security (INSS). Consisted of a questionnaire in two phases. The first, with five questions, was designed to define the final research instrument composed of 15 questions. The research in this study resulted in better understanding on some issues initially raised and indications which may help future studies, aiming to improve the operation of ATMs. Overall, it was evident that the elderly have been conquered by the self-service.

Key words: Information science. Old age assistance. Adaptation psychological. 


\section{Referências}

ABENSUR, E. O. et al. Tendências para o auto-atendimento bancário brasileiro: um enfoque estratégico baseado na teoria das filas. Revista de Administração Mackenzie, São Paulo, a. 4, n.2, p. 39-59, 2004.

ABRAHÃO, J. I.; SILVINO, A. M. D.; SARMET, M. M. Ergonomia, cognição e trabalho informatizado. Psicologia: Teoria e Pesquisa, Brasília, v. 21, n. 2, p. 163-171, maio/ago. 2005.

ARBEX Jr, J. Guerra fria: uma descrição panorâmica. [s.d]. Disponível em: <www.tvcultura.com.br/aloescola/historia/guerrafria/ guerra1/descricaopanoramica.htm>. Acesso em: 3 set. 2009.

BANCO CENTRAL DO BRASIL. Banco de dados. 2008. Disponível em: <www.bacen. gov.br>. Acesso em: 29 maio 2008.

BEAUVOIR, S. A velhice. Rio de Janeiro: Nova Fronteira, 1990.

CERVO, A. L.; BERVIAN P. A. Metodologia científica. São Paulo: McGraw-Hill. 1983.

CONGER, J. A. Quem é a geração X? HSM Management, São Paulo, a. 2, n. 11, p. 128-138, nov./dez. 1998.

DIEESE. Departamento Intersindical de Estatística e Estudos Sociais. A globalização da economia e a informatização do sistema financeiro. 1997. Disponível em: <www.dieese. org.br>. Acesso em: 29 maio 2008.

FEBRABAN. Federação Brasileira de Bancos. Banco de dados. 2008. Disponível em: <www.febraban.org.br>. Acesso em: 29 maio 2008.

GARCEZ LEME, L. E. A gerontologia e o problema do envelhecimento: visão histórica. In: PAPALÉO NETTO, M. (Org.). Tratado de gerontologia. São Paulo: Atheneu, 2007. p. 13-25.

GILBURG, D. Técnicas de gerenciamento para estimular o melhor da geração Y. 2007. Disponível em: <cio.uol.com.br/gestao/2007/11/05/ idgnoticia.2007-11-05.8801133901>. Acesso em: 2 set. 2009.

IBGE. Instituto Brasileiro de Geografia e Estatística. Banco de dados. 2006. Disponível em: <www.ibge.gov.br>. Acesso em: 29 maio 2008.

KUCHINOMACHI, Y.; KUMADA, T. The relationship between the cognitive function decrease of elderly people and the usability of domestic appliances and participation in outside activities. Technology and Disability, v. 11, s. n, p. 169-175, 1999.

LARANGEIRA, S. M. G. Reestruturação produtiva no setor bancário: a realidade dos anos 90. Educação e Sociedade, Campinas, a. 18, n. 61, p. 110-38, dez. 1997.

MAZZONI, A. A.; TORRES, E. F. Contribuições para uma atenção adequada às pessoas idosas nos serviços de caixa bancário de autoatendimento. Florianópolis, Ciência \& Saúde Coletiva, v. 13, n. 4, p. 1227-1236, 2008.

MEIRELLES, F. S.; MAIA, M. C. 2004. Avaliação, evolução e tendências dos gastos e investimentos em tecnologia de informação dos principais bancos nacionais. In: SIMPÓSIO DE ADMINISTRAÇÃO DA PRODUÇÃO LOGÍSTICA E OPERAÇÕES INTERNACIONAIS, VII, São Paulo, 2004. Anais... São Paulo: Simpoi, 2004.

ANJO NETO, M. R.; SOUZA NETO, A. F.; GONÇALVES, J. C. S. Nível de contato e tecnologia: um estudo sobre as atitudes do consumidor de terceira idade e a utilização dos equipamentos de auto-atendimento no setor bancário. In: ENCONTRO NACIONAL DA ASSOCIAÇÃO NACIONAL PÓS-GRADUAÇÃO E PESQUISA E ADMINISTRAÇÃO, 26. Salvador, 2002. Anais..., Salvador: Anpad, 2002.

NETTO, D. F. A importância da cultura como vetor da defesa nacional: Brasil e Estados Unidos numa perspectiva comparada nos séculos XX e XXI. 2007. [s.f]. Dissertação (Mestrado em Relações Internacionais) Programa de Pós-Graduação em Relações Internacionais da Universidade Federal 
Fluminense, Niterói, 2007.

SÃO PAULO. Prefeitura Municipal. Portal institucional. 2008. Disponível em: <www. prefeitura.sp.gov.br>. Acesso em: 28 jun. 2008.

RELATÓRIO BANCÁRIO. Anuário brasileiro de bancos. 2007. Disponível em <www. relatoriobancario.com.br>. Acesso em: 22 nov. 2008.

SIMÕES, R. Corporeidade e terceira idade: a marginalização do corpo do idoso. Piracicaba: Unimep, 1994.

VARGAS, H. S. Psicogeriatria geral. Rio de Janeiro: Guanabara Koogan, 1994.

VILELLA, R. M. Conteúdo, usabilidade e funcionalidade: três dimensões para a avaliação de portais estaduais de governo eletrônico na web. 2003. 263 f. Dissertação (Mestrado em Ciência da Informação) - Escola de Ciência da Informação da Universidade Federal de Minas Gerais. Belo Horizonte, 2003.

WACHOLZ, P. A; FIAMONCINI, F. K. Diferenças intergeracionais no contexto brasileiro: reflexões e perspectivas. Estudos Interdisciplinares sobre o Envelhecimento, Porto Alegre, v. 9, s. n, p. 7-24, 2006.

\section{Notas}

1 Os terminais de autoatendimento são também conhecidos no Brasil como caixas eletrônicos, caixas automáticos, ATMs (Automatic Teller Machines), Banco 24 Horas ou terminais bancários (N. A.).

2 A Associação Brasileira de Normas Técnicas (ABNT). A NBR 15250/2005 foi elaborada no Comitê Brasileiro de Acessibilidade (ABNT/CB40), pela Comissão de Estudo de Acessibilidade em Comunicação (CE-40:000.03). Possui como objetivo fixar os critérios e parâmetros técnicos de acessibilidade a serem observados no projeto, construção, instalação e localização de equipamentos destinados à prestação de informações e serviços de autoatendimento bancário (N.A).

3 Desenho universal é a forma de conceber produtos, meios de comunicação, serviços e ambientes para serem utilizados por todas as pessoas, o maior tempo possível, sem a necessidade de adaptação, beneficiando pessoas de todas as idades e capacidades.

4 Deficiências visuais relacionadas com a dificuldade de diferenciação das cores.

5 A Grande Depressão foi a crise econômica desencadeada a partir de 1929 com a quebra da Bolsa de Valores de Nova Iorque (N. A.).

6 O Diretas Já foi um dos movimentos de maior participação política no Brasil, iniciado em 1983, sob o governo João Batista Figueiredo, último presidente do regime militar. O movimento propôs eleições diretas para o cargo de presidente da República (N. A). 